C Abecassis-Empis, P Reszka, T Steinhaus, A Cowlard, H Biteau, S Welch, G Rein, JL Torero, "Characterisation of Dalmarnock Fire Test One" Experimental Thermal and Fluid Science 32 (7), pp. 1334-1343, 2008. (special Issue Fifth Mediterranean Combustion Symposium)

paper available at the digital repository of the BRE Centre for Fire Safety Engineering:

http://www.era.lib.ed.ac.uk/handle/1842/1152

\title{
Characterisation OF DALMARNOCK Fire Test ONE
}

C Abecassis-Empis, P Reszka, T Steinhaus, A Cowlard, H Biteau, S Welch, G Rein, J L Torero*

BRE Centre for Fire Safety Engineering

The University of Edinburgh, UK

\begin{abstract}
The Dalmarnock Tests comprise a set of fire experiments conducted in a real high-rise building in July 2006. The two main tests took place in identical flats, Test One allowing the fire to develop freely to post-flashover conditions while Test Two incorporated sensorinformed ventilation management. The test compartments were furnished with regular living room/office items and fully instrumented with high sensor densities. The furniture and objects acting as fuel were arranged to provide conditions that favour repeatability. A full description

of the set up of the tests, including fire monitoring sensors, is provided. Focus is on the larger Test One fire for which the major events are reported together with a thorough characterisation of the fire using sensor information. The main aim of the experiments was to collect a comprehensive set of data from a realistic fire scenario that had a resolution compatible with the output of field models. The characterisation of Test One provides a platform with potential for analytical and computational fire model validation.
\end{abstract}

Keywords: Fire; Large-scale tests; Dalmarnock

\section{INTRODUCTION}


Fire Safety Engineering practices are currently going through a rapid process of change. Prescriptive codes and simple analytical tools and numerical models are being substituted by performance-based analysis and complex numerical tools [1]. Experimental studies available for validation are mostly quite dated and the density of instrumentation is mostly designed to use the results for validation of simple analytical expressions or "zone models". Zone models divide compartments into two layers (hot and cold) thus only require spatial resolution that averages an entire zone. A classic example of such tests is the Steckler et al. experiments [2].

A different problem associated with large-scale fire tests is the repeatability of the results. Most large-scale tests tend to produce a set of results that will depart from the results of a repeat of the same test. While simple pool fire experiments [3] or standard large-scale tests [4] are quite repeatable, most realistic fire tests do not follow the same trend. In many cases, the variability of the results is associated with ignition conditions or ventilation changes. For realistic furnishings common ignition sources can lead to drastic variations in the ignition and initial flame spread characteristics. In a similar manner, window breakage and wind changes tend to establish variable ventilation conditions that affect the growth of a fire. Consequently, comparison between deterministic numerical model output (which will always give the same answer for the same input) with realistic fire scenarios is generally deemed unreliable.

For this set of experiments the instrumentation density was set up to provide field measurements with time and spatial resolution compatible with that of field model grid spacing. Thus the problem of averaging is avoided and comparison between models and results can be done at the cell level. The repeatability was addressed by initiating the fire with a large pool fire (in the form of a wastepaper basket with liquid fuel) placed adjacent to a flammable item of furniture. The arrangement guaranteed a large initiation event. Furthermore, the main fuel items were arranged in a configuration very similar to the ISO room corner test [4], with entrainment driving the flames against the flammable corner. The changes in ventilation were managed by either fixing doors open/closed and by breaking window glass at a pre-specified time (Test One) or by remotely controlling the operation of these (Test Two). Details of the setup of both experiments are presented in the following section but only the results of Test One are further discussed.

\section{EXPERIMENTAL SETUP}

The large-scale Dalmarnock Fire Tests involved two main compartment fires held in a 23storey reinforced concrete tower in Dalmarnock, Glasgow (UK) on the $25^{\text {th }}$ and $26^{\text {th }} \mathrm{July}$, 2006. The tests were held in identical two-bedroom single family flats, with the living room set up as the main experimental compartment. Test One, comprising an 'uncontrolled' fire that was allowed to grow past flashover conditions (Plate 1), was held on the $4^{\text {th }}$ floor while Test Two, a more 'controlled' fire, was held directly two floors below. Both experimental compartments were furnished identically as regular living room/office spaces and fully instrumented with a variety of fire monitoring sensors. Test One also included structural 
monitoring sensors as part of a series of demonstrations not directly associated to the fire development. During both tests all sensors were fed into local data loggers and camera hubs that streamed the information live to a remote 'control centre', outside the building. The main variant between both tests was the ventilation conditions. In the first test ventilation conditions were set to allow for flashover to occur. In the second test some doors and windows were operated remotely on the basis of monitoring and with the objective of evacuating the smoke. This meant the 'uncontrolled' Test One fire burned for $19 \mathrm{~min}$ before the fire brigade intervened and Test Two was extinguished when the fire growth could no longer be controlled by

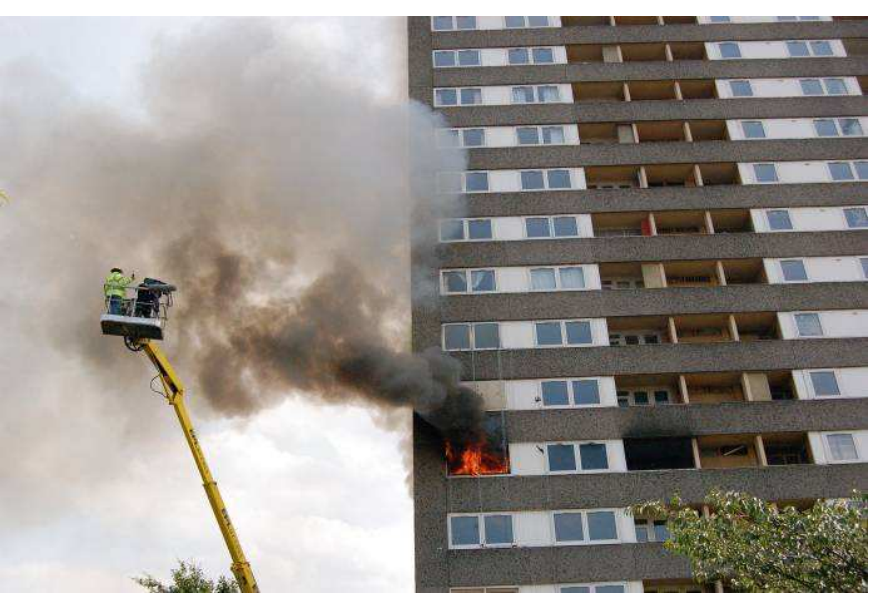

Plate 1. Dalmarnock Fire Test One as seen from the outside, $18.5 \mathrm{~min}$ into the fire. changes in ventilation.

\section{Flat layout}

The flats used were located on the north-side of the building, facing westward. They comprised a central flat corridor off which came two bedrooms, a bathroom and a living room, with a small kitchen off the side of the living room as seen in Fig. 1. The main experimental compartment in both tests was the flats' $2.45 \mathrm{~m}$ high, $3.50 \mathrm{~m}$ by $4.75 \mathrm{~m}$ living room, with a $2.35 \mathrm{~m}$ by $1.18 \mathrm{~m}$ window (2 panes) on the west-facing wall, $1.11 \mathrm{~m}$ from the floor. The compartments were stripped of all their existing contents and an identical furniture layout was used as fuel load in both tests.

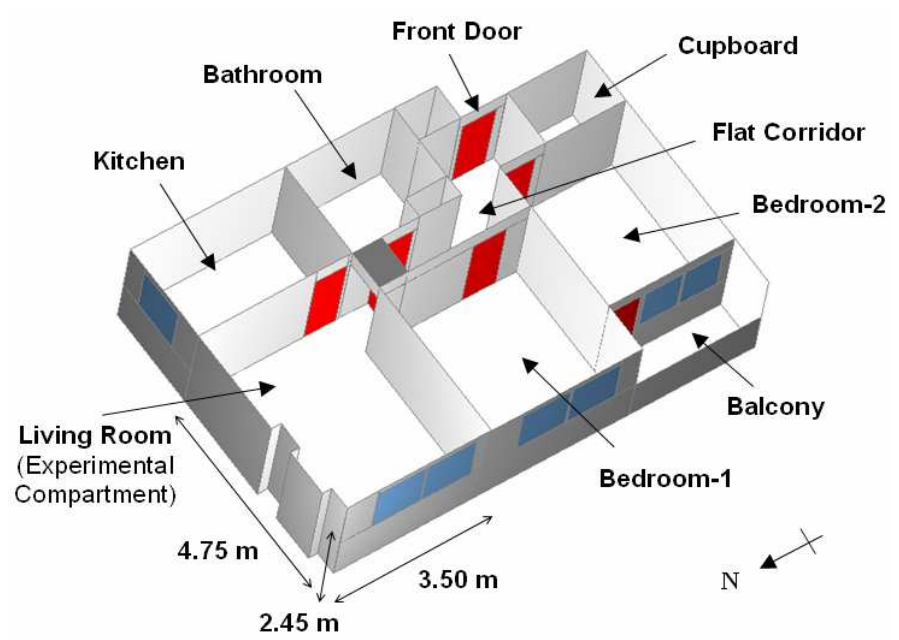

Figure 1. North-west bird's eye view of the flat layout including walls, doors and windows. The front door leading to the main floor access corridor is indicated. The major dimensions of the experimental compartment are labelled.

\section{Fuel distribution}


The general layout was such that most of the fuel was concentrated towards the back of the compartment, away from the window, with a fairly even fuel loading throughout the rest of the compartment. Fig. 2 shows the furniture distribution and Plate 2 illustrates an overview of the compartment before and after the fire.

While the main source of fuel was a two-seat sofa stuffed with flexible polyurethane foam, the compartments also contained two wooden office work desks with computers, each with its own foam-padded chair, three tall wooden bookcases, a short plastic cabinet, three small wooden coffee tables, a range of paper items and two tall plastic lamps. The bookcases were fully-laden with books, video tapes, paper-filled cardboard files, and several other plastic items, as was the small cabinet. The bookcase closest to the sofa also had two plastic containers holding thin cardboard boxes full of polystyrene pellets. Beneath the central computer desk there were two plastic boxes filled with newspapers and magazines. Other minor living room/office items were included to appear as if the compartment was 'in use'. In both cases, a plastic wastepaper basket filled with crumpled newspaper and 300-500 ml of heptane was used as the ignition source. It was placed in-between the sofa and a bookcase, underneath a blanket that was draped over the sofa arm (see Fig. 2 and Plate 2a). Although slightly different amounts of accelerant were used in both tests and the time delays between pouring the accelerant and igniting the fire also varied, this difference was not significant to the general behaviour over the timescale of the fires. The accelerant contributed only to the momentary ignition of each fire and was fully consumed within seconds, but the slightly different ignition protocol enabled to establish the robustness of the ignition conditions in such an arrangement by comparison of the characteristics of both tests during the initial fire growth stage [5].
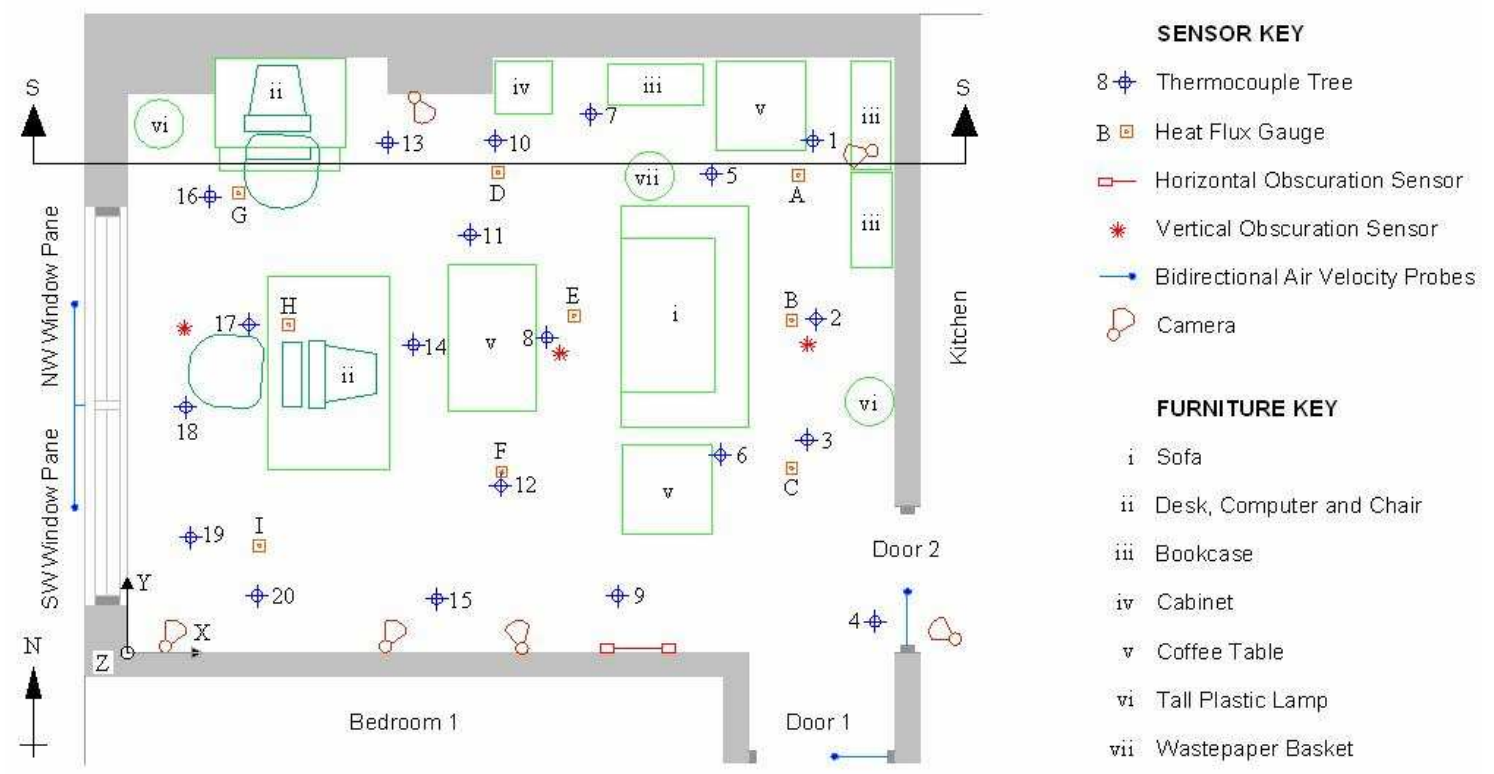

Figure 2. Plan view of experimental compartment showing furniture layout (to scale) and firemonitoring sensor locations (N.B. some sensors were exclusive to Test One). The global coordinate system origin is given (at floor level) and a slice plane section is indicated (S-S). 


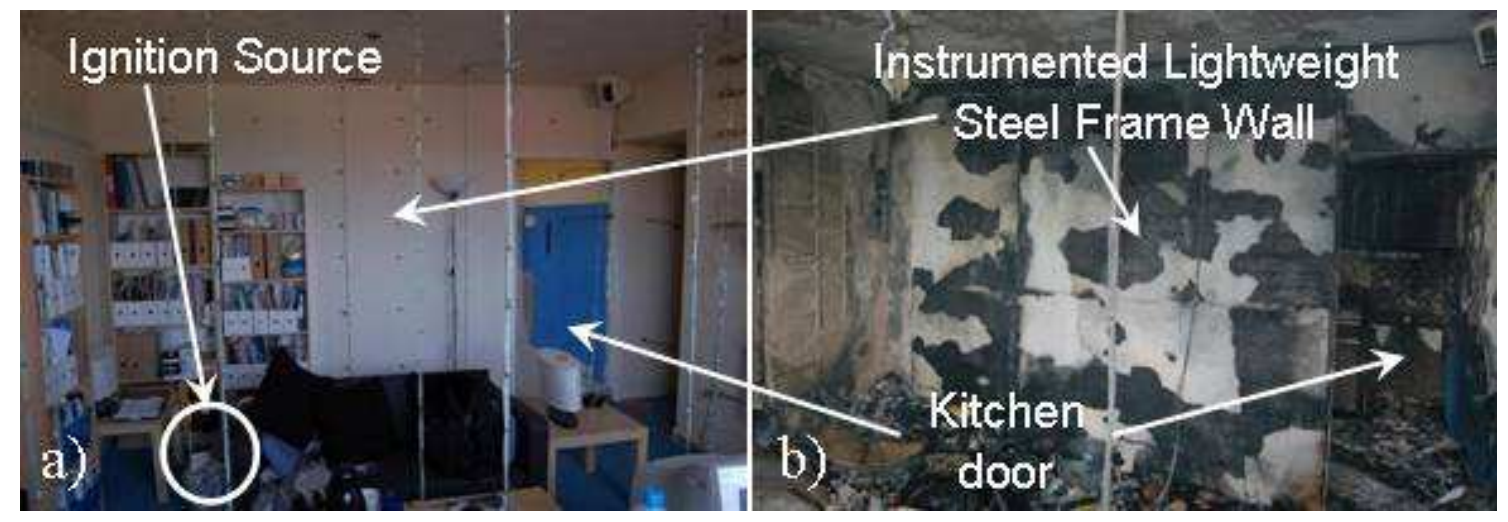

Plate 2. View of the ignition source, bookcases, sofa and nearby items in the experimental compartment both, a) before the fire, and b) after the fire.

\section{Instrumentation}

A variety of sensors were set-up to monitor the fire (see Fig. 2). Twenty thermocouple trees held 12 (Type-KX) thermocouples each. These trees were spread throughout the compartment with a further five small thermocouple trees placed along the window sill. Nine thin-skin calorimeters were used to measure heat flux incident on the compartment ceiling and a further set of these heat flux gauges were mounted on the partition wall shared with the kitchen (20 in Test One, 9 in Test Two). Eight lasers used to measure smoke obscuration were set in emitterreceiver pairs, such that five were horizontally aligned and three were vertically aligned. Three bidirectional air velocity probes, exclusive to Test One, were placed in both the doorway leading to the flat corridor (Door 1) and in the doorway to the kitchen (Door 2) and a further eight probes were placed outside the compartment window. Fig. 2 shows the layout of these fire sensors relative to the furniture distribution. All sensors were connected to a set of central data loggers recording at an average frequency of $0.5 \mathrm{~Hz}$. These were housed in a separate flat, adjacent to the kitchen, protected by a broad structural wall. Several networktype cameras were also used to monitor the fire growth and all data collected was time stamped, both camera and data logger clocks having been synchronised prior to ignition. Similarly, several early warning fire alarm systems and additional CCTV cameras were installed in all rooms in the flat and the fire was monitored live in a 'control room' outside the building [5].

Test One was planned to reach post-flashover conditions, therefore it was of interest to include sensors monitoring structural response. The floor slab above the experimental compartment was heavily instrumented with sensors including 24 thermocouples embedded in the concrete at four different depths and in six different locations, together with 22 strain gauges and nine deflection gauges placed across the top of the slab. Three deflection gauges were also placed in Bedroom-1 to monitor deflections along the height of the partition wall shared with the experimental compartment. The partition wall shared with the kitchen was replaced by a lightweight steel frame wall which was rigged with thermocouples in addition to the gauges measuring heat flux incident on its surface, allowing for a detailed study of its 
performance. A set of six different arrangements of fibre reinforced polymer (FRP) strips embedded in the ceiling was also monitored by thermocouples and strain gauges. Further details of these can be found in related papers $[5,6]$.

\section{Ventilation}

Ventilation parameters were of paramount importance in these tests. In Test One, the window in the main compartment was closed but its doors were both left open. The kitchen window was left partially open, while those of Bedroom-2 were left completely open. The Bedroom-1 window was closed and the main flat door was left ajar. The bathroom compartment remained sealed off throughout the experiment. The building was evacuated (with the exception of firefighters) and data loggers were activated to record ambient conditions.

\section{MAJOR EVENTS}

Test One took place on the $25^{\text {th }}$ July. At 12:23:00 a blow torch was used to ignite the contents of the wastepaper basket and the fire was allowed to grow unconstrained. The blanket dangling over the wastepaper basket caught fire almost immediately, in turn igniting several cushions with fire spreading swiftly to engulf the polyurethane sofa. Four and a half minutes of sofa burning led to ignition of contents of the bookcase adjacent to the sofa and ignition source, near the NE corner of the room. Fire progressed up the bookcase followed by a flashover period about $5 \mathrm{~min}$ after ignition, when ceiling flame projected into the flat corridor and visibility in the main floor access corridor was suddenly reduced. Simultaneous ignition of paper items in several locations throughout the compartment was also indicative of the flashover period. At this point, the smoke layer quickly descended.

Post flashover the visibility in the compartment was drastically reduced, so camera footage provides little information about the subsequent progression of the fire. Nevertheless the fire burnt steadily for the next eight minutes and black smoke was observed seeping out around the compartment window which was not completely sealed or made air tight. About seven minutes after the onset of flashover the kitchen window shattered, even though it had been left partially open, but the experimental compartment window remained intact. The north-west window pane was manually broken at 12:36:21 (over $13 \mathrm{~min}$ after ignition). For a while mostly smoke was seen to billow out with sustained external flaming developing four and a half minutes later, moments after which the second window pane shattered. The fire was allowed to burn freely for a total of $19 \mathrm{~min}$ before the fire brigade intervened to extinguish the fire. A summary of the time to key events is provided in Table 1.

Inspection of the aftermath showed that generally only metal components were left intact. A few samples of partially burned books and other partly combusted items were found, but most of the experimental compartment fuel was consumed in the fire, as can be seen in Plate $2 b$. All thermocouple trees were found to still be in place hence thermocouple data recorded is assumed to relate back to original coordinates registered. 


\begin{tabular}{lcc}
\hline Major events observed & Time (h:m:s) & Time from ignition (s) \\
\hline Growth period & & 0 \\
\hline Ignition & $12: 23: 00$ & 9 \\
Cushions ignite & $12: 23: 09$ & 186 \\
Smoke visible in main corridor & $12: 26: 06$ & 275 \\
Bookcase ignites & $12: 27: 35$ & \\
Flashover period & & 300 \\
\hline Fire engulfs bookcase & $12: 28: 00$ & 315 \\
Flames project to flat corridor ceiling, low & & 323 \\
visibility in main corridor & $12: 28: 15$ & \\
Ignition of paper lamp and table papers & $12: 28: 23$ & 720 \\
Post-flashover period & & \\
\hline Kitchen Window breakage & $12: 35: 00$ & 801 \\
Compartment window forced breakage & & 1080 \\
(NW Pane) & $12: 36: 21$ & 1111 \\
External flaming & $12: 41: 00$ & 1140 \\
Compartment window breakage (SW Pane) & $12: 41: 31$ & 1320 \\
Firemen in, begin to extinguish & $12: 42: 00$ & \\
Mostly Smouldering & $12: 45: 00$ & \\
\hline
\end{tabular}

Table 1. List of major events observed throughout the Test One fire, obtained from camera footage. Respective clock time and time elapsed from ignition are given.

\section{DATA PROCESSING}

Laboratory calibration of the laser smoke obscuration sensors allowed for conversion of the raw voltage data obtained into the form of relative power and as such, percentage obscuration. Thermocouple measurements have been used to determine the height of the smoke layer over time and verified against camera footage. In turn, this enables the use of the laser obscuration sensor data to determine the equivalent extinction coefficient of the smoke layer over time, following the classical methodology based on Bourger's Law [7]. The results of these measurements are presented in Fig. 3. Only data from the horizontal sensors is used as it was found that the vertically-aligned laser smoke obscuration sensors measurements (in Test One) are unreliable.

Just after the onset of flashover all the laser obscuration data is seen to fluctuate erratically, most likely due to heat damage, and therefore is only considered reliable up to this point. Footage from a network camera stationed at $730 \mathrm{~mm}$ from the floor on the wall opposite the horizontal laser smoke obscuration sensors is used for simple verification of the extinction 
coefficient calculations. Jin has stated that once a certain object is visually judged to be "just no longer visible" due to smoke obscuration, the extinction coefficient of the smoke layer at that time is the quotient of three over the distance to that object [7, 8]. The distance to referenced light-reflecting objects in the horizontal line of sight of the footage can be estimated from plan drawings of the furnished compartment. These optically estimated extinction coefficients show good agreement with the laser-obtained extinction coefficients, inclusive of a data point within the flashover period, as illustrated in Fig. 3. In particular it appears to match the data obtained from the lowest set of horizontal laser obscuration sensors (Laser 1), which was located at a similar height.

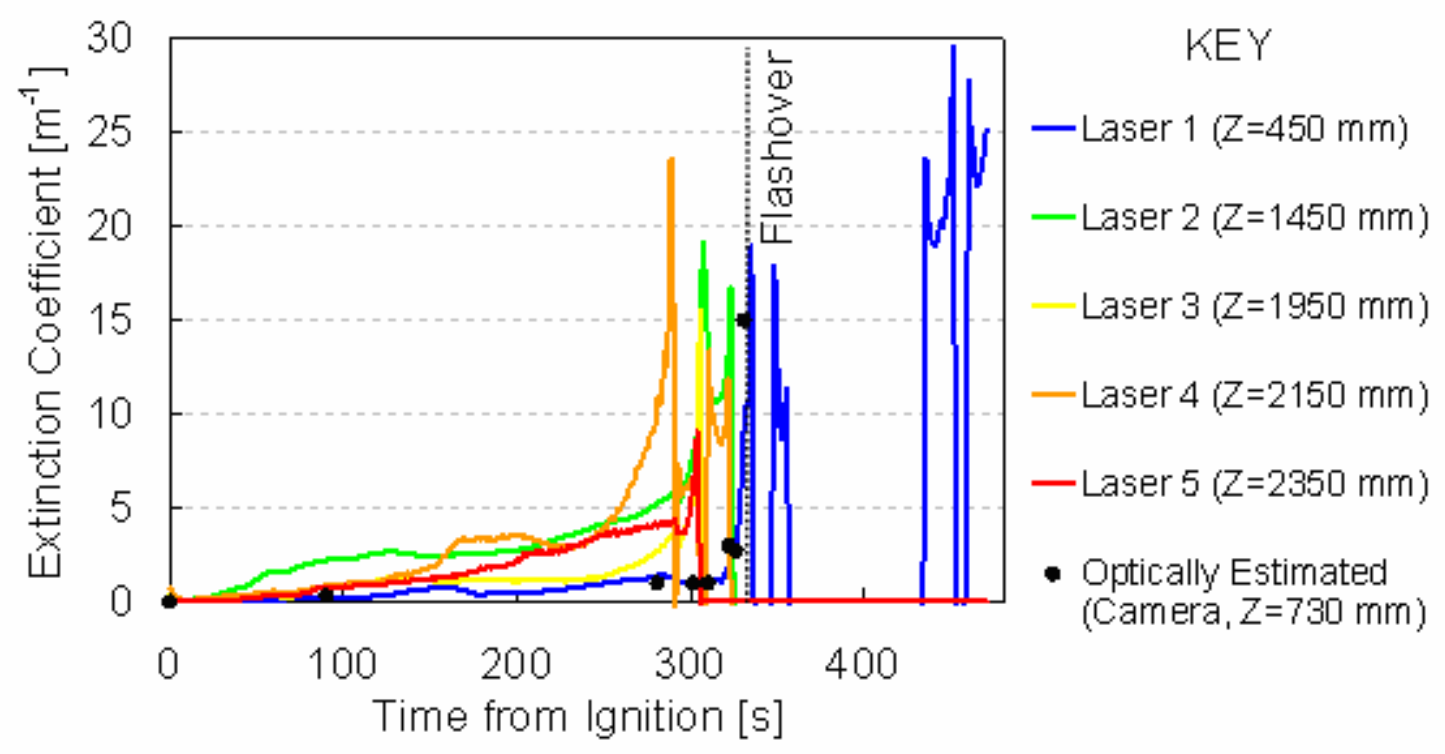

Figure 3. Extinction coefficient data calculated from horizontal laser measurements of smoke obscuration at five different heights (see Fig. 2 for coordinate origin) inclusive of measurements obtained from a simple correlation using visual estimates from camera footage.

The verified steep increase in extinction coefficient around the onset of flashover illustrated in Fig. 3 allows for the trend to be extrapolated, since evidence from footage also shows that shortly after $300 \mathrm{~s}$ into the fire the smoke layer descended to the ground. In addition, the lowest laser obscuration sensor (Laser 1) output some data around 440-470 s that could be seen to fit such a trend. Although its location is thought to have allowed this sensor to last longer than the others the reliability of this information is uncertain, particularly because high extinction coefficients equate to very low voltage and any errors become a larger percentage of the weaker signal. Therefore a range of bounds have been assumed for the extinction coefficient beyond flashover. Post-flashover it is assumed the extinction coefficients remain constant. The upper bound stabilisation value estimated is an extinction coefficient of $25 \mathrm{~m}^{-1}$, taking into account the last set of data output by Laser 1 . The lower bound stabilisation value is taken at an extinction coefficient of $14 \mathrm{~m}^{-1}$ since this is the last value computed from several sensor outputs before they became damaged. 
While it is appreciated that the laser sensors were only measuring smoke obscuration in one planar location and that the density is likely to have been spatially varied, particularly since the measurements were taken next to a wall, it is also deemed unlikely to have varied significantly given the dimensions of the compartment and its ventilation conditions. Therefore, throughout the compartment, it is assumed that the extinction coefficient has only a vertical variation. Furthermore, a single value of the extinction coefficient of the smoke layer is calculated by averaging the values corresponding to laser obscuration sensors submerged in the smoke layer as it grew over time. For the average extinction coefficient of the smoke layer post-flashover, a gradual trend towards a stabilisation value of $19.5 \mathrm{~m}^{-1}$ is assumed as a mean of the estimated bounds.

The thermocouple data has been corrected for radiation according to the method described by Welch et al. [9]. All thermocouple readings are corrected to 'gas-phase' values with the exception of the uppermost thermocouple in each of the 20 trees, since these were in contact with the ceiling. The temperature correction reveals radiation errors to be overall negligible in this case, since the average maximum temperature correction is of the order of $\pm 7^{\circ} \mathrm{C}$. Some localised corrections are of greater significance, with the maximum correction of $80^{\circ} \mathrm{C}$ occurring during the period of greatest temperature stratification, particularly when the hot layer initially developed. It is of note that most temperature corrections of similar magnitude coincide in time and correspond to thermocouples in the vicinity of the sofa and the central coffee table, as expected. The overall corrections due to radiation are relatively low compared to average compartment temperatures. It should be noted that the average smoke layer extinction coefficient used as part of these corrections may also contribute towards errors due to the uncertainties inherent in their own computation. Nevertheless, corrected gas-phase temperatures are used throughout the analyses and this process allowed for the identification of a few damaged thermocouples for which substitute values are spatially interpolated from neighbouring thermocouple readings.

The thin-skin heat flux gauges used throughout the experiment consist of copper discs embedded in plasterboard which have been calibrated using a radiative panel and a calibrated heat flux meter. All raw heat flux gauge data has been correspondingly post-processed into net incident heat flux values before use in analysis. Further details on the heat flux calibration process highlight the limitations of the gauges employed [5, 6]. Conversion of the raw bidirectional velocity probe data has been performed as per literature detailing the calibration of such probes in a wind tunnel at BRE [9, 10].

\section{CHARACTERISATION OF THE INTERNAL FIRE}

\section{Average temperature-time curve}

The compartment average gas-phase temperature-time curve, presented in Fig. 4, shows the general behaviour to match observations and sequence of major events. In order to fully 
characterise the fire, six key time steps have been chosen for comparison of different data sets at consecutive points in time: Time Step 1 at $201 \mathrm{~s}$ represents the initial localised sofa fire; Time Step 2 at 251 s, the fire growth period as it began to spread; Time Step 3 at $351 \mathrm{~s}$, conditions just after flashover; Time Step 4, post-flashover steady-state conditions at $420 \mathrm{~s}$; Time Step 5, a period of steady temperature rise post steady-state at $661 \mathrm{~s}$ and Time Step 6 at $901 \mathrm{~s}$ represents the period of peak average compartment temperatures once the first window pane broke. No subsequent time steps are taken since the fire was not allowed to selfextinguish.

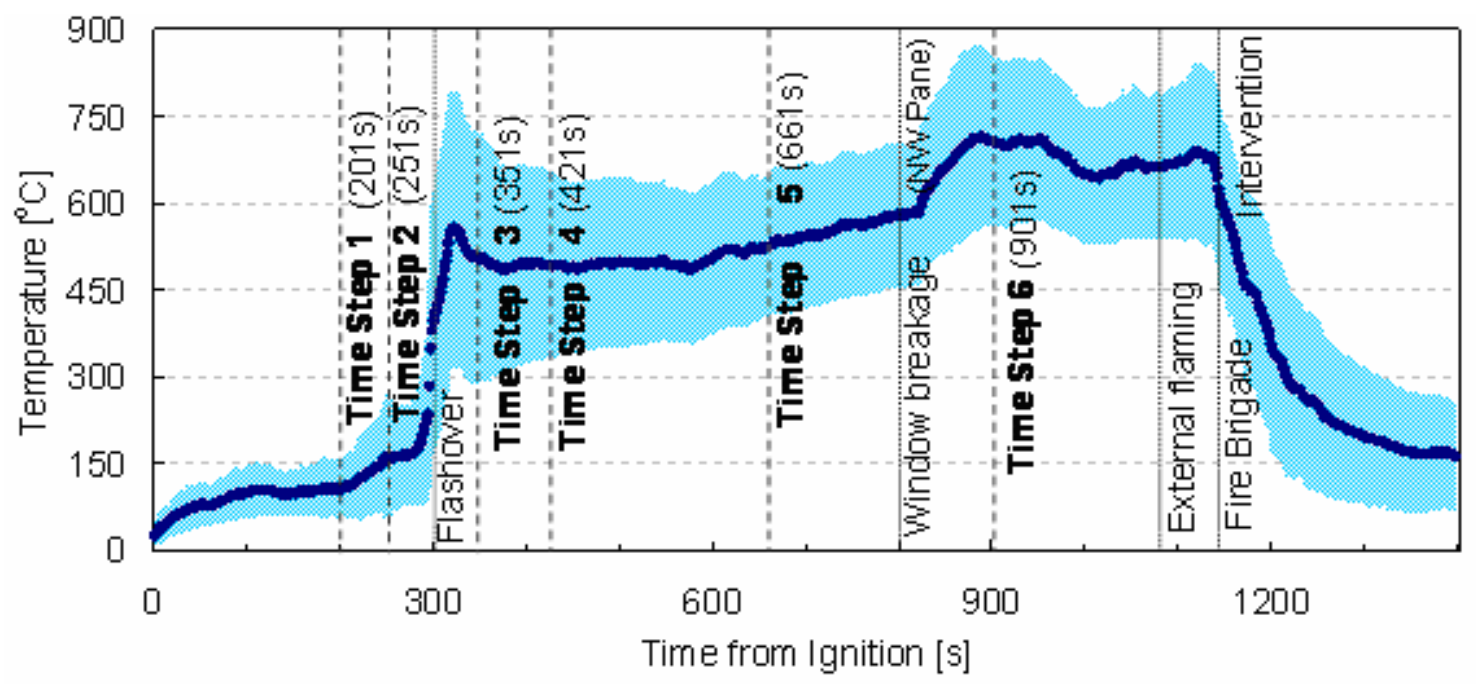

Figure 4. Gas-phase average compartment temperature-time variation with a shaded region indicating the standard deviation of temperature throughout the compartment. Vertical dashed lines indicate time steps used for analysis and dotted lines represent time of some major events, as labelled.

\section{Temperature contour plots}

Gas-phase temperature contour plots through several planes across the compartment have been generated, at each of the selected time steps, using SigmaPlot ${ }^{\circledR}$ (SigmaPlot 10.0, Systat Software Inc., San Jose, CA). Although thermocouple trees were not arranged in orthogonal lines, slice planes are taken at best-fit lines through the trees such that no tree falls outwith 0.3 $\mathrm{m}$ of the slice plane, therefore no 3D data smoothing is required. Eleven thermocouples between the heights of 450-2400 $\mathrm{mm}$ are used as the uppermost thermocouple in each tree was in contact with the ceiling and hence is excluded. The plots indicate the evolution of the fire as well as the spatial temperature variation. Contour plots given in Fig. 5 highlight the different stages of the fire represented by the slice plane S-S (encompassing thermocouple Trees 1,5,7,10,13 and 16), indicated in Fig. 2, crossing the compartment east-west through the initial seat of the fire. Fig. 2 also shows the global origin from which the contour plot axes indicate distance in millimetres. The transition of flashover is evident between Time Steps 2-3 (Figs. 5b, 5c) by the change from a localised fire to multiple spots of intense burning and high temperatures throughout the compartment, with the descent of the smoke layer. Although the bookcases and a computer station seem to be contributing significantly towards the 
temperature increase there is a shift towards greater temperature homogeneity seen in Time Step 4 (Fig. 5d), which is further evident in Time Step 5 (Fig. 5e), concurring with the reduction in standard deviation of mean compartment temperatures noted in Fig. 4. Once the first window pane has broken, Time Step 6 (Fig. 5f) highlights the marked increase in compartment temperature as the partially-combusted fuel is consumed.
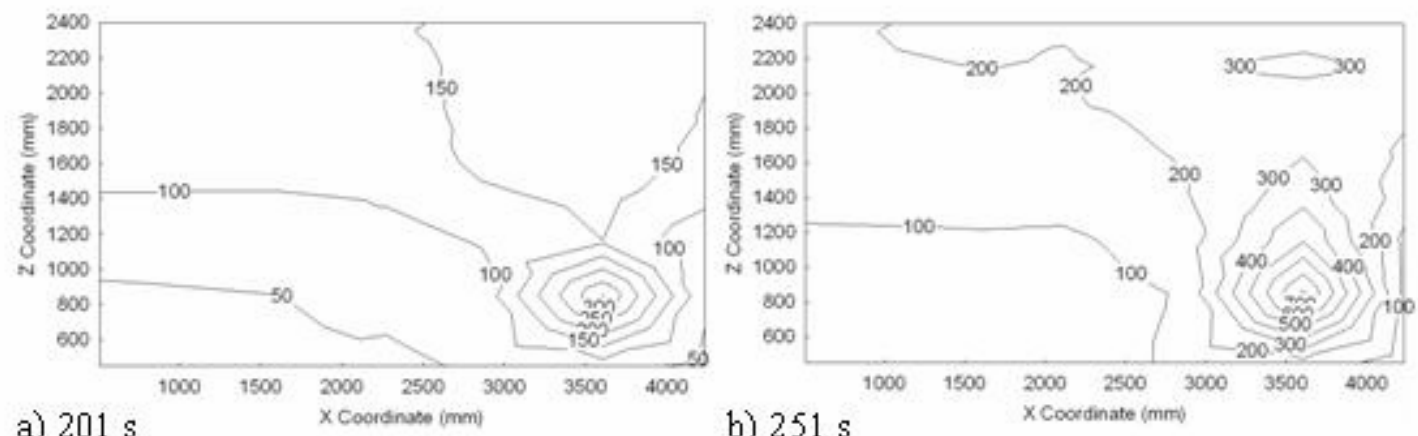

b) $251 \mathrm{~s}$
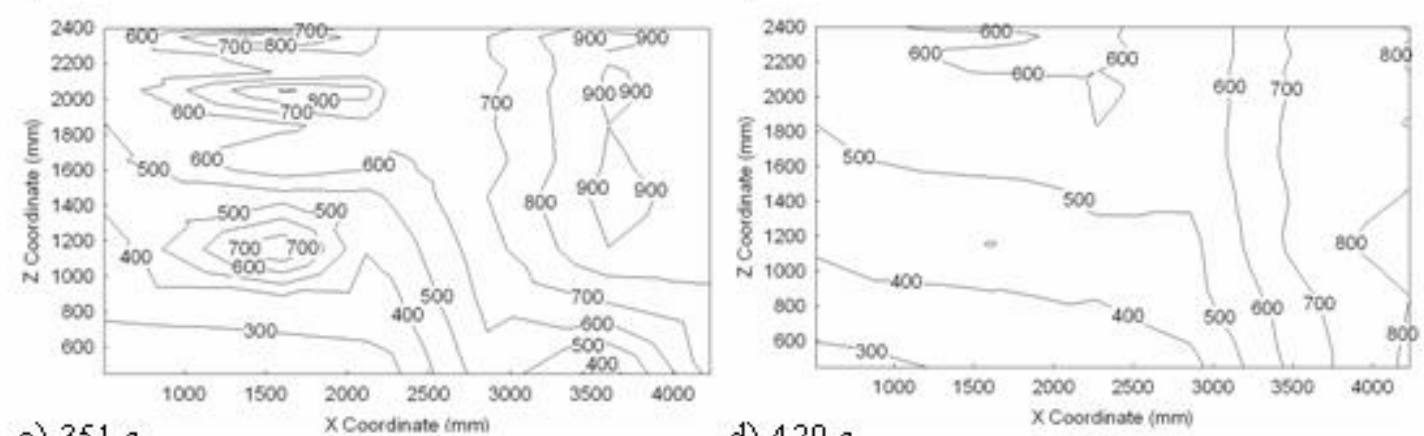

c) $351 \mathrm{~s}$

d) $420 \mathrm{~s}$
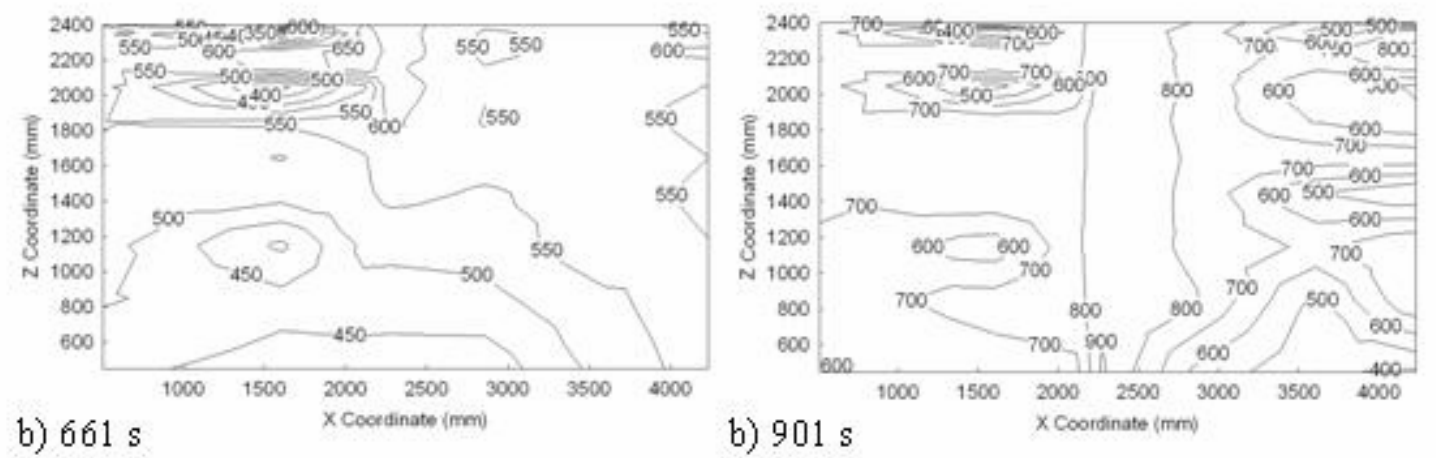

b) $901 \mathrm{~s}$

Figure 5. Gas temperature contours (in ${ }^{\circ} \mathrm{C}$ ) taken from section $\mathrm{S}-\mathrm{S}$ with axes values reading distances from the global origin (see Fig. 2). Plots appear in the chronological order of each Time Step, at specified times from ignition.

\section{Temperature distribution in concrete floor slab above the fire compartment}

The thermocouples monitoring the concrete floor slab above the fire indicate a delay in temperature increase with relation to the gas-phase fire. As expected, the thermocouples embedded lowest in the concrete (i.e. closest to the fire compartment) only rose to a few hundred degrees compared to maximum compartment gas-phase temperatures in the 900$1000^{\circ} \mathrm{C}$ range. Temperature distribution across the concrete indicates highest temperatures 
measured directly above the initial seat of the fire, however conduction is poor in concrete and the temperature variation with depth is large such that all measurements throughout the top of the slab show no more than a $25^{\circ} \mathrm{C}$ increase from ambient conditions. Fig. 6 shows the temperature distribution measured by four thermocouples embedded at different depths in the slab, directly above the sofa. Although only one plot is shown, this pattern is characteristic of all floor slab measurement locations, with concurrent timing of distinct temperature changes.

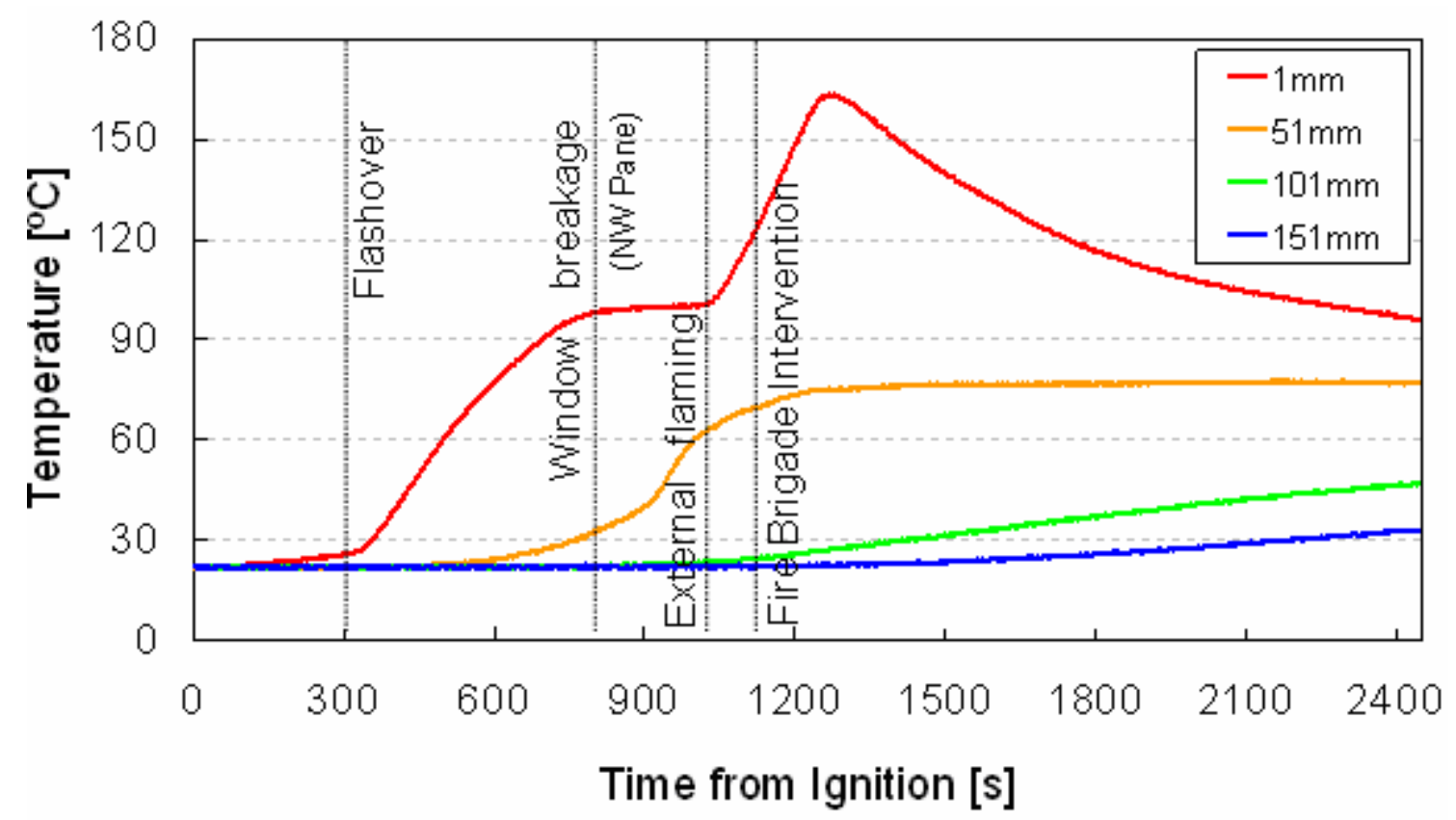

Figure 6. Temperature profiles $\left(\right.$ in ${ }^{\circ} \mathrm{C}$ ) from thermocouples embedded in the concrete floor slab directly above the centre of the sofa, varying with height from the bottom of the floor slab as indicated in the key. Timing of some major events is represented by vertical dotted lines, as labelled.

While the concrete temperatures are scarcely affected during the fire growth period, there is a distinct increase in temperature at the onset of flashover in the lowermost thermocouples. The thermocouples embedded $51 \mathrm{~mm}$ up into the concrete see the effects of flashover only $5 \mathrm{~min}$ after the event whereas those embedded further up undergo only a minor temperature rise during the actual fire. It is also interesting to note that the concrete temperatures peak at least two minutes after the fire brigade intervened, when the average compartment temperature was already dropping. This delayed response in temperature rise only highlights the poor thermal diffusivity properties of concrete, also noted by its slow cooling period due to these same low heat transfer properties. A separate in-depth analysis of the structural monitoring sensor information has been conducted with the aim of furthering the understanding of structural concrete behaviour in fire [5].

\section{Heat flux to the surroundings}

Heat flux measurements have also been used to characterise the fire. Spatial variation of heat flux can lead to varying severity of structural exposure to fire, rendering heat flux an important fire characteristic for structural analysis. Patterns of peak net heat flux incident on 
the ceiling over time correlate to sharp rises in gas-phase temperature and to some extent anticipate the delayed heating within the concrete slab, since the heating is directly related to the heat flux incident on the ceiling surface [5]. Contours of heat flux incident on the partition wall shared with the kitchen have been used to analyse the effect of the fire on the lightweight steel frame wall [6]. The heat flux distributions on the ceiling (horizontal) and on this partition wall (vertical) provide a global overview of the insult of the fire to its surroundings.

\section{Total heat release rate}

An approximate fire size has been determined in terms of total heat release rate (HRR) from characterisation of the bidirectional velocity probe data using the principle of oxygen depletion calorimetry [11]. Since no calorimeter or gas sampling measurements are available, the calculation has been based on the assumption that all oxygen ( $23 \%$ air, by mass) was consumed within the compartment, giving an upper bound estimate of HRR. This study is only possible for the period when fire flows become significantly dominant over ambient flows, in this case around Time Step 2. Hence, the HRR shown for the initial fire growth period is only indicative of that expected (Fig. 7). For the majority of the post-flashover period only the six probes located in the two compartment doorways are used for calculation of HRR. Although this velocity probe data is very localised and fluctuates considerably, together with a number of assumptions it allows for an estimate of characteristic HRR throughout the fire.

Total gas mass inflow and outflow derived from the velocity probe data have been found to be imbalanced, particularly in the early post-flashover period where there seems to be a deficit of mass inflow. There are a variety of possible reasons for this variation, namely the limited number of probes and the location of these probes. The lowermost probes were still $430 \mathrm{~mm}$ and $460 \mathrm{~mm}$ off the ground, which may not have accounted for the majority of the inflow area since the smoke layer had, by then, descended considerably. Also, the local temperature values used for calculation of gas density in both cases are those measured by thermocouples in Tree 4 which is located in between the two doors (see Fig. 2). This tree is a horizontal distance of $250 \mathrm{~mm}$ away from the probes in Door 2 and $93 \mathrm{~mm}$ from those in Door 1 (negligible vertical discrepancy), so the same local gas density has been assumed for probes at similar heights in both doors, when in reality they are likely to be quite different due to ventilation relative to the flat geometry.

An average of both mass inflow and outflow has been used to ensure the balance of both. Assuming complete combustion of all oxygen, Huggett's formula is used to estimate the heat release rate from the mass flow data [11]. Due to the number of assumptions involved in the assessment of HRR, a check is performed using estimated ventilation factors to compute mass inflow rates for different periods throughout the ventilation-controlled fire. Compartment ventilation factors are calculated for each ventilation condition, in the form of Vent Cases. Vent Case 1 assumes 30\% of the kitchen window area was open and that 50\% equivalent of the flat corridor area (height reduction) was open to simulate the initial ventilation conditions. 
Once the kitchen window shattered this is taken into account in the ventilation factor of Vent Case 2. Similarly, when the NW window pane broke in the compartment, this occurrence is integrated in the conditions for Vent Case 3 and final Vent Case 4 includes ventilation from both compartment window panes further to the kitchen window and initial conditions. Again, using Huggett's formula and assuming complete combustion of oxygen to obtain basic HRR values, these cases are plotted and indicate good agreement between both methods, illustrated in Fig. 7. The HRR general trend is also seen to correspond to that of the average compartment temperature (Fig. 4) in that it grows from a quasi-steady state $3 \mathrm{MW}$ fire to a larger $\sim 5 \mathrm{MW}$ fire around the time when the first compartment window pane breaks. Although this is a relatively crude measurement of HRR it provides a good indication of the fire size.

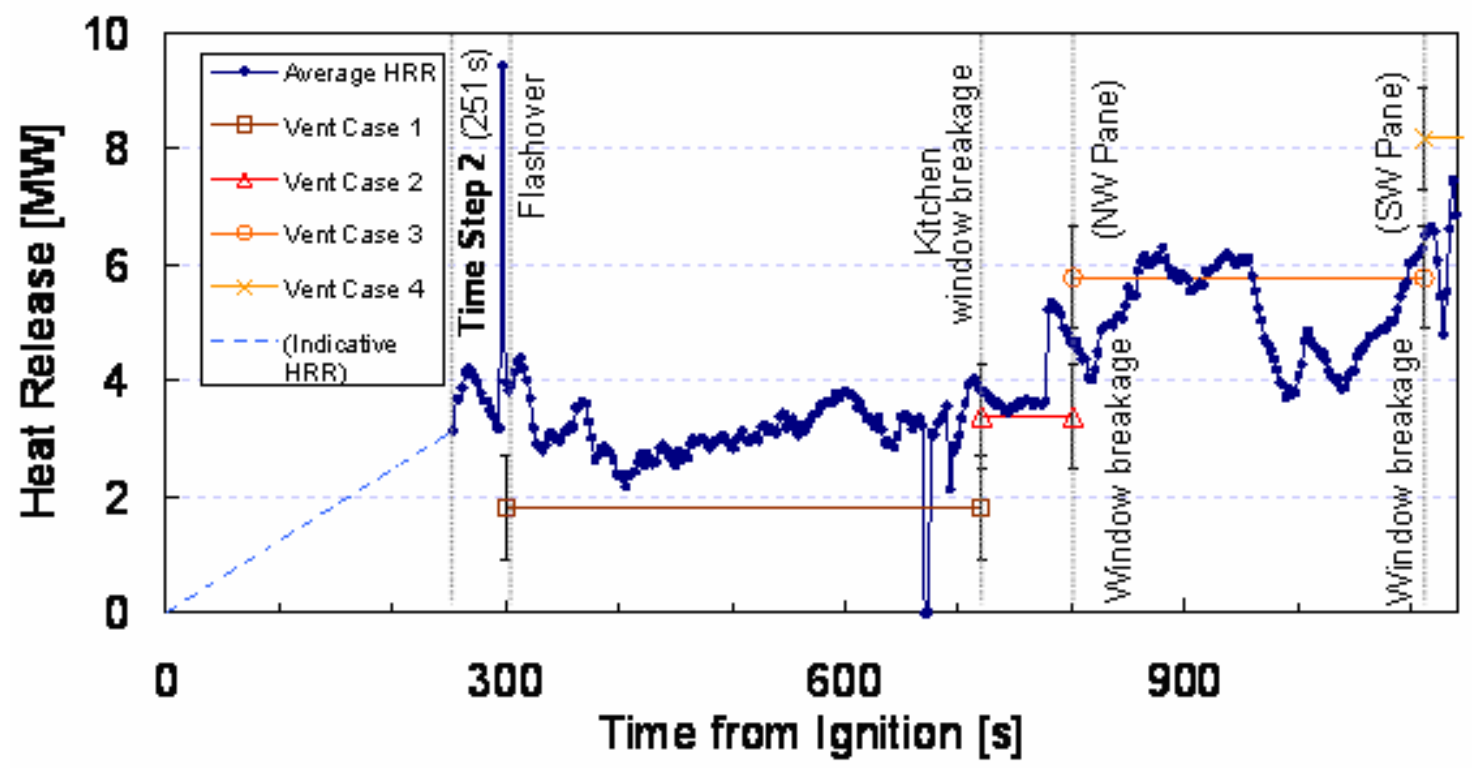

Figure 7. Heat release rate of the fire as estimated using the principle of oxygen depletion. Alternative simplified estimates using ventilation factors for the calculation of HRR are shown as Vent Cases corresponding to different ventilation change events. These include error bars and indicate good agreement with the HRR calculated from velocity probe data. Timing of some major events is represented by vertical dotted lines, as labelled.

Laboratory testing has also been conducted using calorimetry to determine the average HRR of individual replica items and several material samples taken from major furnishings in the Dalmarnock Fire Test. This includes large-scale calorimetry under an exhaust hood, burning a replica of the sofa used in the experimental compartments as well as one of the fully laden bookcase modules. Other material samples have been tested in the cone calorimeter to determine the HRR and critical heat flux for the ignition of each [5]. This data has also been used to verify that the magnitude of the global HRR evolution is within the expected range. Together with the information characterising this test, this data is seen as invaluable for the use of these experiments as a validation tool for computational models. 


\section{SUMMARY AND EXPLOITATION}

A realistic fire test has been conducted under conditions that are particularly relevant to field model validation. The results cover the entire range of application of such tools. Although only a summary of the results is presented, a complete set of data can be requested from the corresponding author.

The simple nature of these tests, furnished with regular tenement items in a real building, increases the applicability of the characterised fire test data for validation of practical fire dynamics. Additionally, a similar analysis of Test Two has shown the repeatability of this experimental arrangement to be highly robust to variations in environmental conditions [5]. The use of these experiments has already contributed towards extending the current understanding of the complex dynamics of fire and the inherent difficulties of predicting its evolution. This increases our understanding of fire safety by highlighting the strengths and limitations of fire safety tools and practices in real fires.

Test One has been used as a validation tool in an evaluation scheme for the current state-ofthe-art of computational fluid dynamic tools, by comparison of numerous 'blind' a priori fire development predictions submitted by a range of parties, given the initial setup and boundary conditions [5]. The study demonstrated considerable disparity between the predicted fires not only between themselves, but also differing from the experimental data. These results reflect on the strengths and limitations of current fire simulations in engineering which are conducted in the absence of actual fire development data. However, the general behaviour captured by many of the simulations provides fire features that are good enough to be applied towards engineering objectives. The tests have also been used to investigate the capability of current fire modelling tools to simulate realistic fires, where a posteriori knowledge of fire characteristics is used as input [5]. This comparison serves as a validation tool for certain faculties of CFD models as well as emphasising some of the current limitations of their use.

\section{ACKNOWLEDGMENTS}

The authors acknowledge the help of the many organisations and funding agencies involved in the Dalmarnock Fire Tests. Thanks go to BBC Horizon, EPSRC, The University of Edinburgh, Glasgow Housing Authority, Strathclyde Fire Brigade, Glasgow Caledonian University, Lion TV, Arup, BRE, Xtralis and Powerwall Systems Ltd. Special thanks to many of our colleagues at the BRE Centre of Fire Safety Engineering, at The University of Edinburgh, without the help of whom the tests would not have been successful.

Financial support from the BRE Trust for C. Abecassis-Empis and A. Cowlard is gratefully acknowledged. The work reported in this paper has formed part of FireGrid, www.firegrid.org. This research has been funded by the Technology Strategy Board along with contributions from the other partners in FireGrid. 


\section{REFERENCES}

[1] S Lamont, B Lane, A Jowsey, J Torero, A Usmani, G. Flint, Innovative structural engineering for tall buildings in fire, Structural Engineering International 16 (2) (2006) 142-147.

[2] KD Steckler, JG Quintiere, WJ Rinkinen, Flow Induced by Fire in a Compartment, National Bureau of Standards, Washington DC, 1982. NBSIR-82-25-20.

[3] DD Drysdale, An Introduction to Fire Dynamics, $2^{\text {nd }}$ Edition, John Wiley \& Sons, U.K., 1998.

[4] British Standards, Fire Tests on Building Materials and Structures, BSI, U.K., 1993. BS476: Part 33: 1993 (ISO 9705:1993).

[5] G Rein, C Abecassis Empis, R Carvel (Eds.), The Dalmarnock Fire Tests: Experiments and Modelling, School of Engineering and Electronics, University of Edinburgh, U.K., 2007. ISBN 978-0-9557497-0-4.

[6] A Amundarain, JL Torero, A Usmani, AM Al-Remal, Assessment of the thermal efficiency, structure and fire resistance of lightweight building systems for optimised design, The Third Int. Conf. on Structural Engineering, Mechanics and Computation, Cape Town, Sept. 2007.

[7] T Jin, Visibility and human behaviour in fire smoke, in: P.J. DiNenno et al. (Eds.), The SFPE Handbook of Fire Protection Engineering, $3^{\text {rd }}$ Edition, National Fire Protection Association, Massachusetts, U.S.A., 2002, pp. 2-42 - 2-53.

[8] GW Mulholland, Smoke production and properties, in: P.J. DiNenno et al. (Eds.), The SFPE Handbook of Fire Protection Engineering, $3^{\text {rd }}$ Edition, National Fire Protection Association, Massachusetts, U.S.A., 2002, pp. 2-258 - 2-268.

[9] S Welch, A Jowsey, S Deeny, R Morgan, JL Torero, BRE large compartment fire tests characterising post-flashover fires for model validation, Fire Safety Journal (2007), doi:10.1016/j.firesaf.2007.04.002.

[10] BJ McCaffrey, G Heskestad, A robust bidirectional low-velocity probe for flame and fire application, Combustion and Flame 26 (1979) 125-127.

[11] C Huggett, Estimation of rate of heat release by means of oxygen consumption measurements, Fire and Materials, 4 (1980) 61-65.

C Abecassis-Empis, P Reszka, T Steinhaus, A Cowlard, H Biteau, S Welch, G Rein, JL Torero, "Characterisation of Dalmarnock Fire Test One" Experimental Thermal and Fluid Science 32 (7), pp. 1334-1343, 2008. (special Issue Fifth Mediterranean Combustion Symposium)

paper available at the digital repository of the BRE Centre for Fire Safety Engineering: http://www.era.lib.ed.ac.uk/handle/1842/1152 